\title{
Positive allosteric modulation of the 5-HT1A receptor by indole-based synthetic cannabinoids abused by humans
}

\author{
Hideaki Yano ${ }^{* 1,4}$, Pramisha Adhikari', Sett Naing ${ }^{1}$, Alexander F. Hoffman ${ }^{2}$, \\ Michael H. Baumann³, Carl R. Lupica², Lei Shi*,1
}

${ }^{1}$ Computational Chemistry and Molecular Biophysics Unit, ${ }^{2}$ Electrophysiology Research Section, and ${ }^{3}$ Designer Drug Research Unit, Intramural Research Program, National Institute on Drug Abuse, National Institutes of Health, Baltimore, Maryland 21224, ${ }^{4}$ current address: Department of Pharmaceutical Sciences, Northeastern University, Boston, Massachusetts 02115.

Keywords: synthetic cannabinoids, $\mathrm{CB} 1$ receptor, $5-\mathrm{HT}_{1 \mathrm{~A}}$ receptor, positive allosteric modulation. 


\section{SUPPLEMENTAL METHODS}

\section{DNA constructs}

Human receptor constructs ( $D 2 R, 5-H T_{1 A} R, 5-H T_{2 A} R, 5-H T_{2 B} R$, a1AR, a2AR, and CB1 R) were modified at the $\mathrm{N}$-terminus with in frame fusion of a signal peptide followed by a Flag epitope tag for enhanced cell surface expression. ${ }^{1}$ These receptors were fused to Renilla Luciferase 8 (Rluc;

provided by Dr. S. Gambhir, Stanford University, Stanford, CA) as described previously. ${ }^{2}$ The following fusion human $\mathrm{G}$ protein constructs were used for bioluminescence resonance energy transfer (BRET) assays: Gai191-Venus, Gaq-150Venus (inserted positions noted). Untagged $\beta y$ subunits G $\beta 1$ and Gy7 were also used for co-transfection. G protein chaperone Ric8 $\mathrm{A}^{2}$ (kind gift from Dr. Gregory Tall) was co-transfected with Gaq150-Venus construct. The cAMP sensor with YFP-Epac-Rluc (CAMYEL) was obtained from ATCC (no. MBA-277). All the constructs were confirmed by sequencing analysis.

\section{Radioligand binding assays}

Radioligand binding assays were conducted similarly to methods previously described. ${ }^{3-5}$ Cells were maintained as described in BRET assays above. Membranes were prepared from HEK-293T cells transiently expressing the $5 \mathrm{HT}_{1 \mathrm{~A}} \mathrm{R} .{ }^{3}$ Briefly, cells were detached using Earle's Balanced Salt Solution (EBSS) containing 5 mM EDTA (Life Technologies) and centrifuged at $3200 \mathrm{rpm}$ for $10 \mathrm{~min}$ to obtain cell pellets. The supernatant was discarded, and the cells were lysed in $10 \mathrm{~mL}$ hypotonic lysis buffer $\left(5 \mathrm{mM} \mathrm{MgCl} 2.6 \mathrm{H}_{2} \mathrm{O}, 5 \mathrm{mM}\right.$ Tris, $\mathrm{pH} 7.4$ at $\left.4^{\circ} \mathrm{C}\right)$. Membranes were centrifuged at $14,500 \mathrm{rpm}$ for $30 \mathrm{~min}$ at $4^{\circ} \mathrm{C}$, supernatant was discarded, and the resulting pellet was resuspended in $10 \mathrm{~mL}$ of freshly made binding buffer. Membranes were homogenized at 30,000 rpm three times for $10 \mathrm{~s}$ each (Kinematica PT2500E). Membrane protein concentrations were determined using bicinchoninic acid assay (Pierce).

EBSS buffer was used for $\left[{ }^{3} \mathrm{H}\right]$ WAY100635 binding. $25 \mu \mathrm{g}$ of membrane proteins with $1 \mathrm{nM}$ $\left[{ }^{3} \mathrm{H}\right]$ WAY100635 were used in a final reaction volume of $200 \mu \mathrm{L}$. Freshly harvested membranes 
were incubated with the corresponding compounds in $1 \%$ DMSO final concentration and radioligands for $80-120 \mathrm{~min}$ at room temperature with a 10 min shaking in between. Non-specific binding of $\left[{ }^{3} \mathrm{H}\right]$ WAY100635 was determined in the presence of $10 \mu \mathrm{M}$ cold WAY100635. The reaction was terminated by rapid filtration through a pre-soaked $(0.05 \%$ polyethyleneimine for 80 120 mins) 96 well filter plate (PerkinElmer, Uni-filter-96 GF/B) using a 96-well plate harvester (Brandel) followed by three washes with ice-cold binding buffer. Filters were left to dry for $\sim 2 \mathrm{~h}$ and soaked overnight in $60 \mu \mathrm{L}$ scintillation cocktail (Perkin Elmer, MicroScint 20). Bound radioactivity was detected by a scintillation counter (Perkin Elmer, MicroBeta Microplate Counter).

All experiments were performed at least 5 times, and data were analyzed using Prism Software (GraphPad). Saturation binding data were fitted to one-site specific binding and competition binding data were fitted to non-linear regression (one-site competition). Data are presented as means \pm SEM and statistical significance was calculated using two-tailed unpaired t-tests. The $I_{50}$ values obtained from competition experiments were used to calculate the corresponding $K_{\mathrm{i}}$ values using the Cheng-Prusoff equation. ${ }^{6}$

\section{Animals}

Wildtype (WT) C57BL/6J mice and CB1R knockout mice $\left(\mathrm{CNR} 1^{-/}\right)$bred on a C57BL/6J background $^{7,8}$ were used for slice electrophysiology and core body temperature measurement experiments. Animals were housed with food and water available ad libitum in temperature $(22 \pm$ $2^{\circ} \mathrm{C}$ )- and humidity $(45 \pm 5 \%)$-controlled rooms and were maintained on a $12 \mathrm{hr}$ light/dark cycle (lights on: 7:00 a.m.-7:00 p.m.). They were experimentally naive at the start of the study and were maintained in accordance with $\mathrm{NIH}$ guidelines. All studies were approved by the Institutional Care and Use Committee of the Intramural Research Program, National Institute on Drug Abuse. 


\section{SUPPLEMENTARY FIGURES}

Supplementary Figure 1. Characterization of orthosteric interactions of SCs at several aminergic receptors by BRET assays. A. Scheme for the engagement BRET between receptor and $G$ protein. B-F. Dose response curves for BRET between D2R-Rluc and Gi-Venus (B), 5-HT $2 A$ RRluc and Gq-Venus (C), 5-HT $2 \mathrm{~B}$ R-Rluc and Gq-Venus (D), $\alpha 1 \mathrm{AR}-\mathrm{Rluc}$ and Gq-Venus (E), $\alpha 2 A R-$ Rluc and Gi-Venus (F). For panels B-F, increasing concentrations of JWH-018 (orange), AM2201 (blue), UR-144 (red), XLR-11 (green), and corresponding agonists were applied, whereby agonists are dopamine (B), 5-HT (C-D), and norepinephrine (E-F). The error bars represent S.E.M.

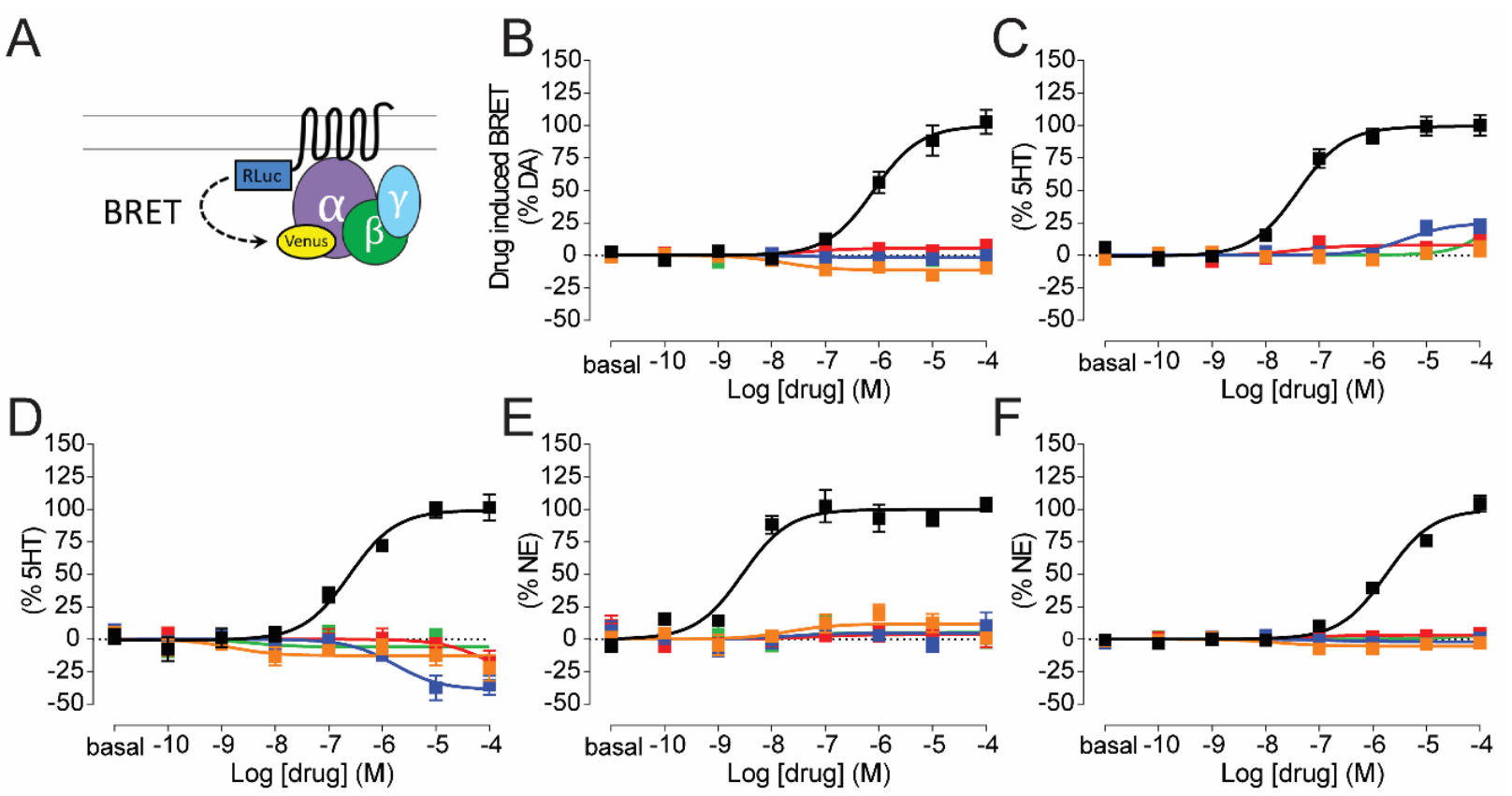


Supplementary Figure 2. Characterization of allosteric interaction and antagonism of SCs at several aminergic receptors by BRET assays. A. Scheme for the engagement BRET between receptor and $\mathrm{G}$ protein in the presence of agonist. B-F. Dose response curves for BRET between D2R-Rluc and Gi-Venus (B), 5-HT $2 \mathrm{~A} R-$ Rluc and Gq-Venus (C), 5-HT $2 \mathrm{~B}$ R-Rluc and Gq-Venus (D), a1AR-Rluc and Gq-Venus (E), a2AR-Rluc and Gi-Venus (F). For panels B-F, increasing concentrations of the corresponding antagonists (black open squares), JWH-018 (orange), AM2201 (blue), UR-144 (red), XLR-11 (green) were applied in the presence of a fixed concentration $\left(10^{-6} \mathrm{M}\right)$ of the corresponding agonists, whereby the antagonists are eticlopride (B), clozapine (C-D), prazocine (E), and yohimbine (F), and the agonists are dopamine (B), 5-HT (CD), and norepinephrine (E-F). The error bars represent S.E.M.

A
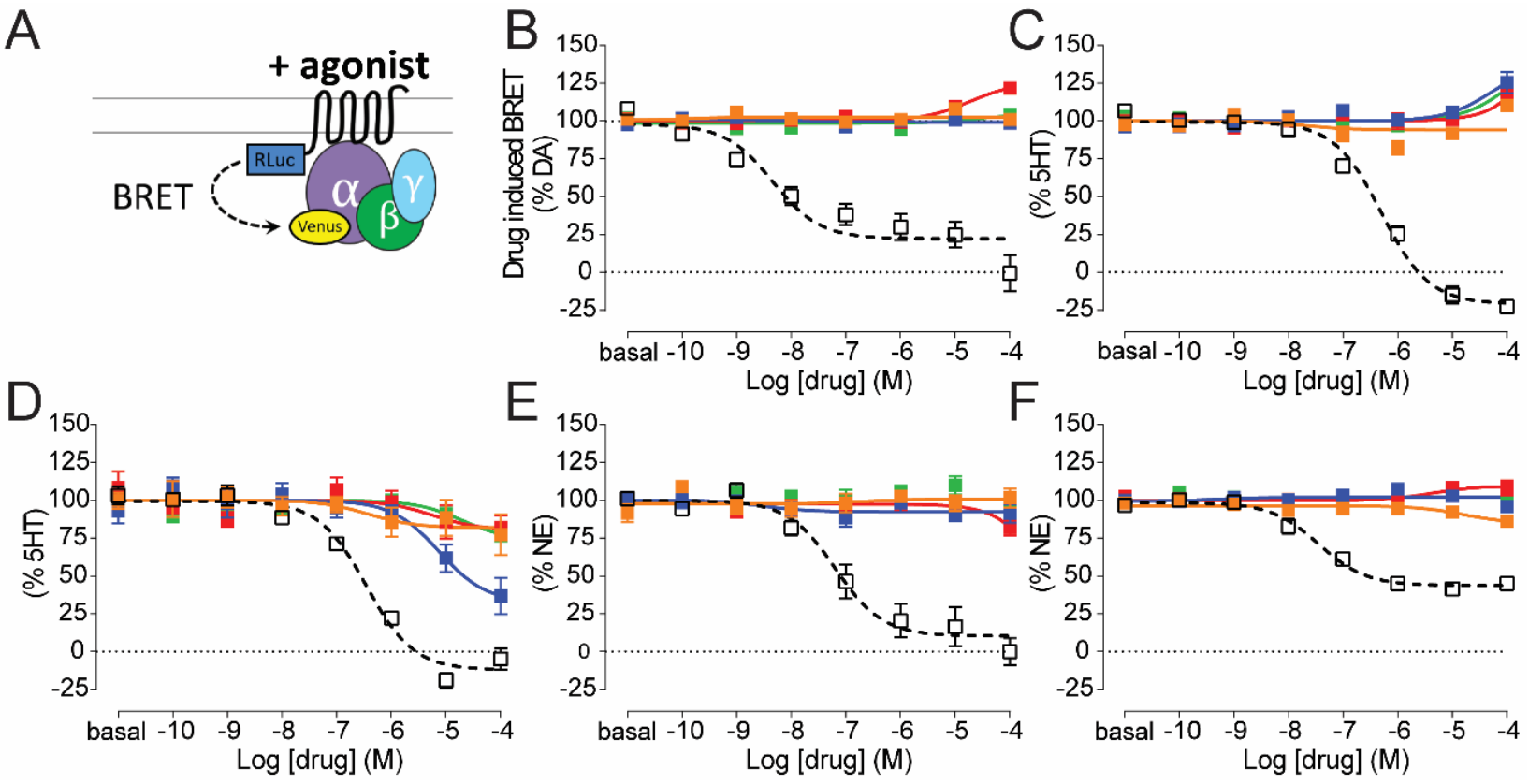
Supplementary Figure 3. Positive allosteric modulation by synthetic cannabinoids at $5-\mathrm{HT}_{1 \mathrm{~A}} \mathrm{Rs}$. A-B. Dose response curves for the engagement BRET between 5-HT ${ }_{1 A} R-R l u c$ and Gi-Venus: A. 5-HT (black), 5-HT in the presence of $10^{-5} \mathrm{M} \mathrm{AM} 2201$ (blue), 5-HT in the presence of $10^{-5} \mathrm{M} \mathrm{JWH}-$ 018 (orange); B. 8-OH-DPAT (black), 8-OH-DPAT in the presence of 10-5 M AM2201 (blue), 8OH-DPAT in the presence of 10-5 $\mathrm{M}$ JWH-018 (orange). The error bars represent S.E.M. Oneway analysis of variance followed by post hoc Tukey test was used for $E_{\max }$ comparison. ${ }^{*} p<0.05$ against 5-HT or 8-OH-DPAT.
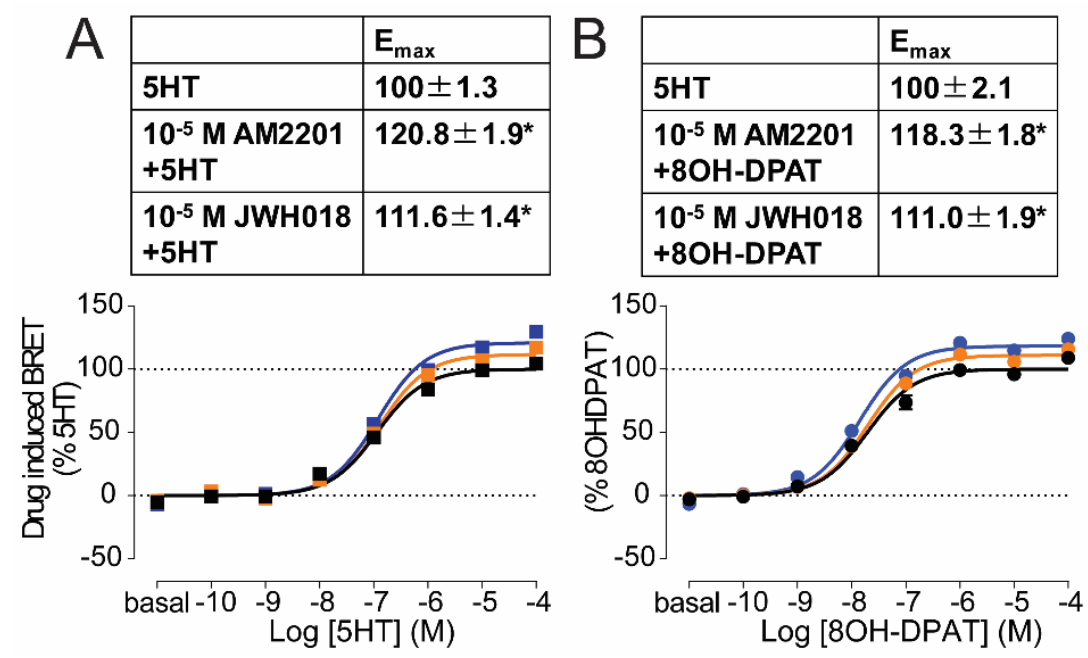
Supplementary Figure 4. AM2201 allosterically modulates 5-HT binding at 5-HT $1 \mathrm{~A}$. A. Competitive binding of 5-HT against $1 \mathrm{nM}\left[{ }^{3} \mathrm{H}\right]$ WAY100635 in the presence of $30 \mu \mathrm{M} \mathrm{AM} 2201$, or in its absence. Specific binding is shown in \% normalized to maximum value of $0 \mu \mathrm{M}$ AM2201. B. Competitive binding of AM2201 against 1 nM [ $\left.{ }^{3} \mathrm{H}\right]$ WAY100635. The error bars represent S.E.M. of 3 experiments performed in triplicate (see Supplementary Table 2 for binding parameters and statistical comparisons).
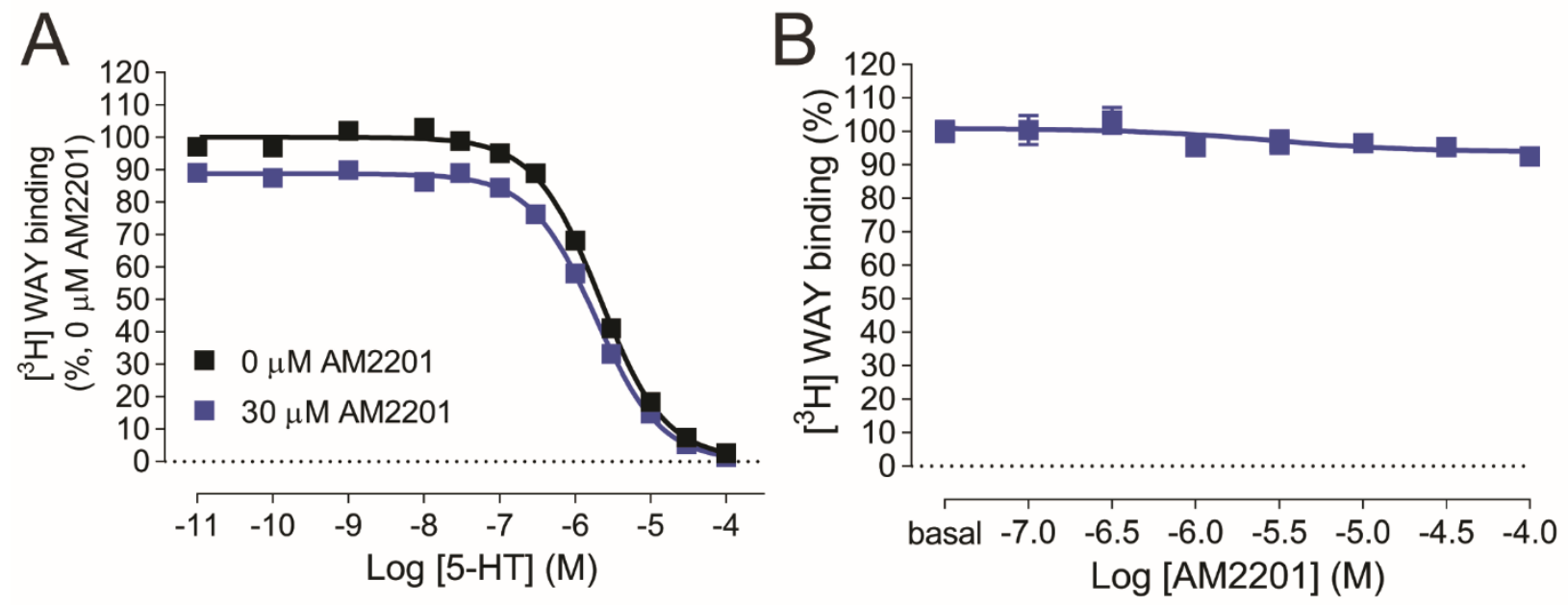
Supplementary Figure 5. $5-\mathrm{HT}$-induced current change $\left(\Delta \mathrm{l}_{\text {hold }}\right)$ in voltage clamp $(-55 \mathrm{mV})$ is inhibited by $5-\mathrm{HT}_{1 \mathrm{~A}} \mathrm{R}$-selective antagonist WAY100635. A. Average time course (mean $\pm \mathrm{SEM}$ ) of 5-HT-induced change in holding current $(\mathrm{pA})$ during perfusion with $3 \mu \mathrm{M}$ (light gray) or $30 \mu \mathrm{M}$ (dark gray) 5 -HT $3 \mu \mathrm{M}$ followed by $10 \mu \mathrm{M}$ baclofen in brain slices obtained from wildtype mice. Note that baclofen still produced outward currents following $3 \mu \mathrm{M} 5-\mathrm{HT}$, confirming the presence of GIRK in these neurons. B. Peak change in holding current (pA) for individual cells for $30 \mu \mathrm{M} 5$ $\mathrm{HT}$ (circle symbol) and $30 \mu \mathrm{M}$ 5-HT in the presence of 300 nM WAY100635 (square symbol). The mean and $95 \%$ confidence intervals are shown. ${ }^{* *} \mathrm{P}<0.01$ vs. $30 \mu \mathrm{M} 5-\mathrm{HT}$ (t-test comparison).
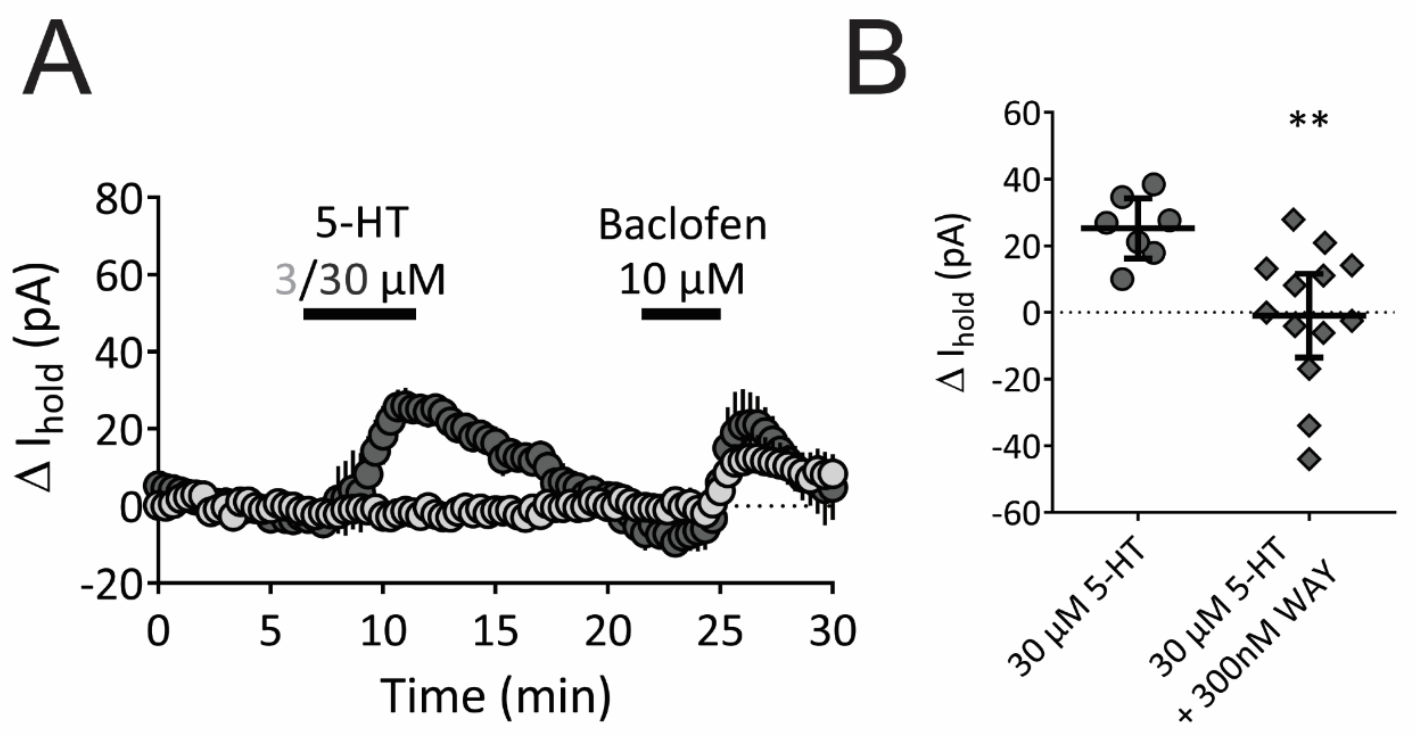
Supplementary Figure 6. Absence of $I_{\text {hold }}$ change with AM2201 or JWH-018 alone. A. Average time course (mean \pm SEM) of holding current $(\mathrm{pA})$ with perfusion of $0.1 \%$ DMSO vehicle (black), $10 \mu \mathrm{M}$ AM2201 (blue), or $10 \mu \mathrm{M}$ JWH-018 (orange) in brain slices obtained from CNR1 ${ }^{-/-}$mice. B. Peak change in holding current $(p A)$ for individual cells for $\mathbf{A}$. The mean and $95 \%$ confidence intervals are shown. No statistically significant differences among groups were observed $\left(F_{(2,15)}\right.$ $=0.2439, p=0.7866$, one-way analysis of variance) .
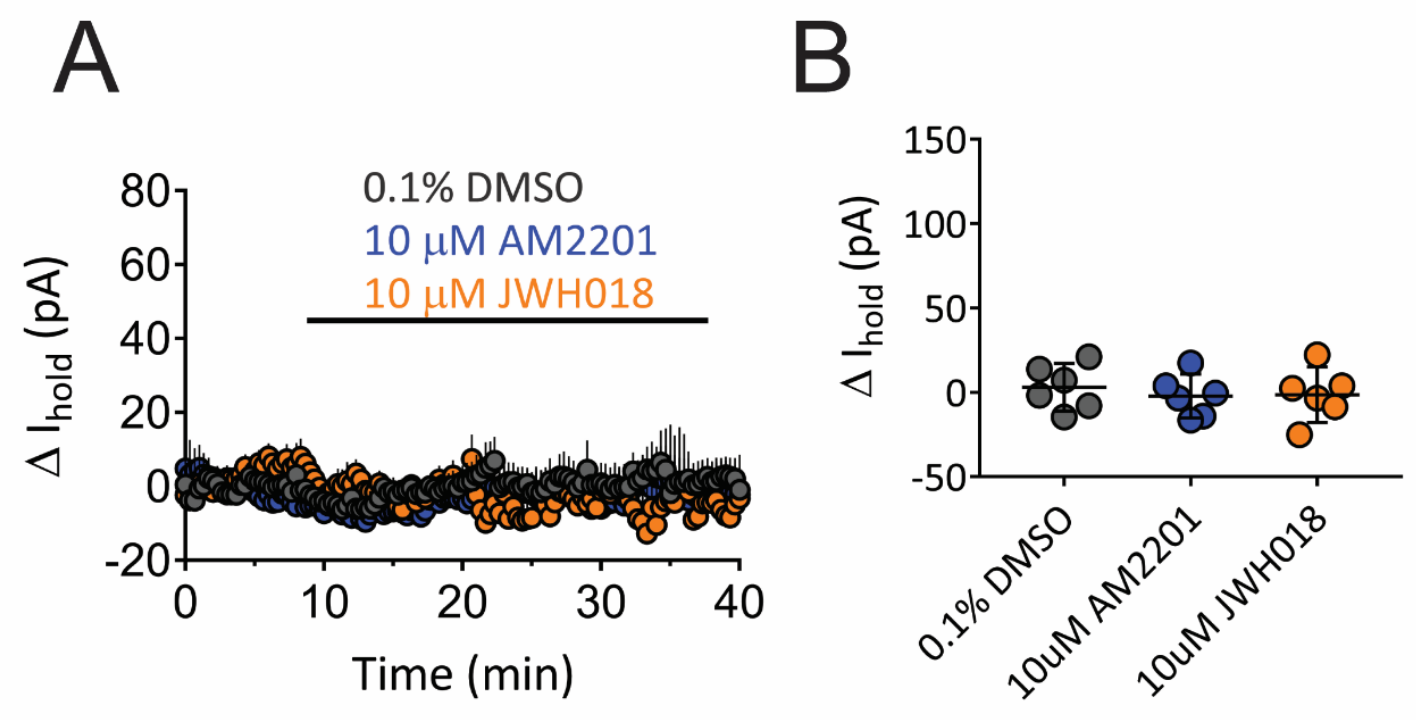
Supplementary Figure 7. 5- $\mathrm{HT}_{1 \mathrm{~A}} \mathrm{R}$-specific ligand-induced hypothermia. A. Core temperature measurement after acute injections of 0 (blue) or 3.0 (green) mg/kg 8-OH-DPAT i.p. following vehicle (filled symbol) or $10.0 \mathrm{mg} / \mathrm{kg}$ WAY100635 (open symbol) s.c. pretreatment (20 min prior to 8-OH-DPAT injection). B. Area under curve (AUC) for each dose condition in $\mathbf{A}$ is plotted. The error bars represent S.E.M. $n=4$ mice per group. One-way analysis of variance followed by post hoc Tukey test was used.

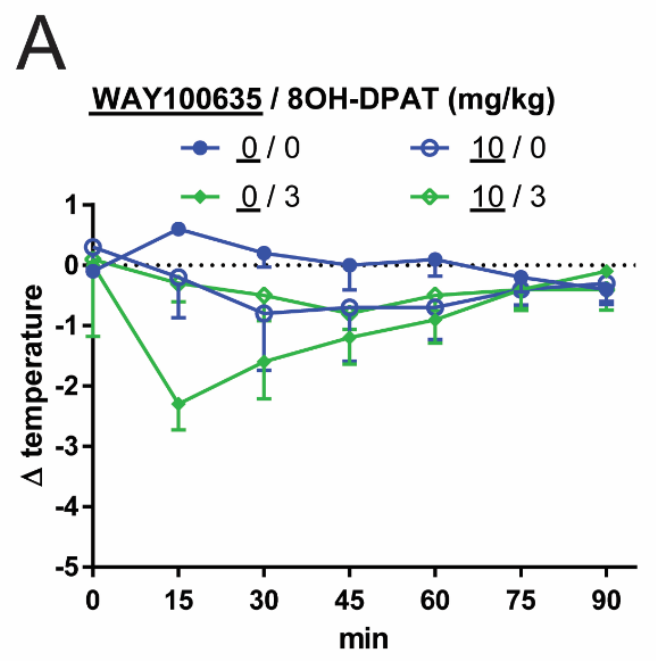

B

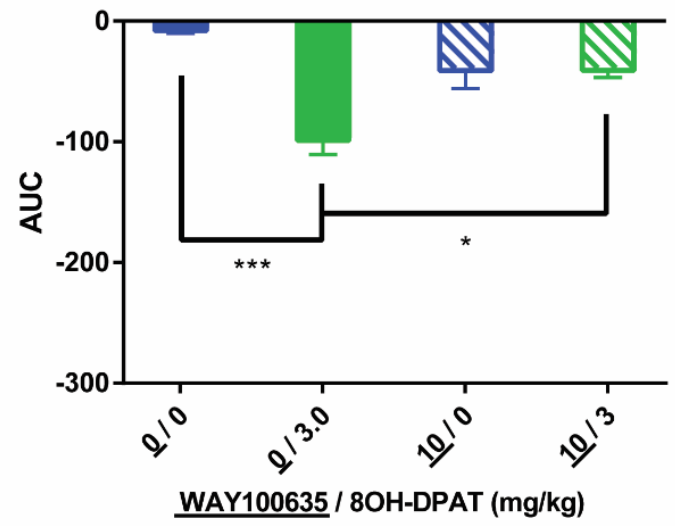


Supplementary Figure 8. Chemical structures of JWH-018, AM2201, UR-144 and XLR-11.
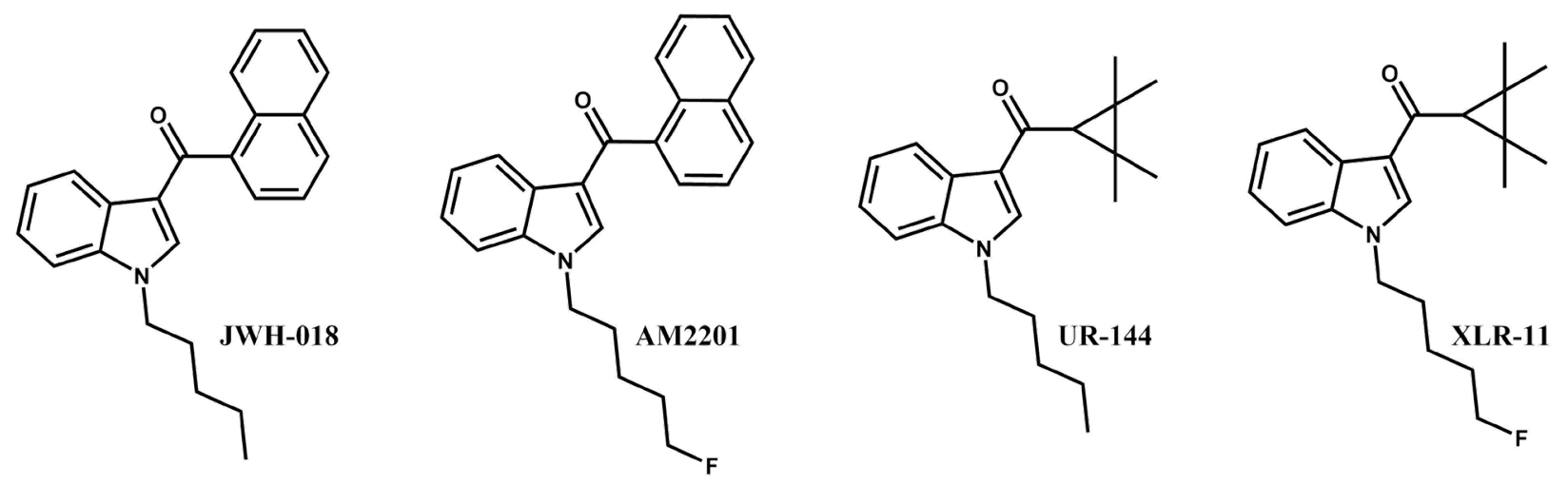


\section{SUPPLEMENTARY TABLES}

Supplementary Table 1. Pharmacological comparison of synthetic cannabinoid ligands. $p E_{50}, E_{\max }, \mathrm{pIC}_{50}$, and $I_{\max }$ values are means \pm S.E.M. of 3 or more experiments performed in triplicate.

\begin{tabular}{|c|c|c|c|c|c|c|c|c|c|c|}
\hline & \multicolumn{2}{|l|}{ CB1R/Gi } & \multicolumn{2}{|c|}{$5-\mathrm{HT}_{1 \mathrm{~A}} \mathrm{R} / \mathrm{Gi}$} & \multicolumn{2}{|c|}{$5-\mathrm{HT}_{1 \mathrm{~A}} \mathrm{R} / \mathrm{Gi}+5-\mathrm{HT}$} & \multicolumn{2}{|c|}{$5-\mathrm{HT}_{1 \mathrm{~A}} \mathrm{R} / \mathrm{cAMP}$} & \multicolumn{2}{|c|}{$5-\mathrm{HT}_{1 \mathrm{~A}} \mathrm{R} / \mathrm{CAMP}+5-\mathrm{HT}$} \\
\hline & $\mathrm{pEC}_{50}$ & $E_{\max }(\%)$ & $p E C_{50}$ & $E_{\max }(\%)$ & $p E C_{50}$ or $\mathrm{pIC}_{50}$ & $E_{\max }$ or $I_{\max }(\%)$ & $p C_{50}$ & $E_{\max }(\%)$ & $p E C_{50}$ or $p C_{50}$ & $\mathrm{E}_{\max }$ or $I_{\max }(\%)$ \\
\hline $5-\mathrm{HT}$ & $\mathrm{ND}^{\mathrm{a}^{*}}$ & $N D^{b^{*}}$ & $6.92 \pm 0.08$ & $100.0 \pm 2.6$ & - & - & $8.14 \pm 0.10$ & $\begin{array}{l}100.0 \pm 4.5 \\
\left(10^{-6} \mathrm{M}\right)\end{array}$ & - & - \\
\hline WAY100635 & - & - & - & - & $7.06 \pm 0.11$ & $7.4 \pm 3.6^{\#}$ & - & - & $6.82 \pm 0.06$ & $-50.7 \pm 3.2^{\#}$ \\
\hline $\mathrm{THC}$ & $6.03 \pm 0.13$ & $72.9 \pm 4.4^{*}$ & $\mathrm{ND}^{\mathrm{a} \#}$ & $N D^{\mathrm{b} \#}$ & $N D^{a}$ & $N D^{c}$ & - & - & - & - \\
\hline CP55940 & $6.18 \pm 0.10$ & $100.0 \pm 4.0$ & ND ${ }^{\text {a\# }}$ & $N D^{b \#}$ & $N^{a}$ & $N^{c}$ & - & - & - & - \\
\hline JWH-018 & $6.47 \pm 0.12$ & $89.6 \pm 3.9$ & $\mathrm{ND}^{\mathrm{a} \#}$ & $N D^{\mathrm{b \#}}$ & $4.60 \pm 0.30$ & $128.4 \pm 5.9^{\#}$ & - & - & $5.83 \pm 0.40$ & $122.6 \pm 4.1^{\#}$ \\
\hline AM2201 & $6.88 \pm 0.11$ & $95.9 \pm 3.7$ & $\mathrm{ND}^{\mathrm{a} \#}$ & $N D^{\mathrm{b \#}}$ & $5.69 \pm 0.26$ & $133.5 \pm 3.9^{\#}$ & - & - & $4.79 \pm 0.37$ & $133.3 \pm 7.8^{\#}$ \\
\hline UR-144 & $5.78 \pm 0.11$ & $108.0 \pm 5.0$ & $\mathrm{ND}^{\mathrm{a} \#}$ & ND ${ }^{\mathrm{b} \#}$ & $N D^{a}$ & $N D^{c}$ & - & - & - & - \\
\hline XLR-11 & $6.14 \pm 0.07$ & $123.5 \pm 3.4^{*}$ & $\mathrm{ND}^{\mathrm{a \#}}$ & $N D^{\mathrm{b \#}}$ & $N D^{a}$ & $N^{c}$ & - & - & - & - \\
\hline
\end{tabular}

$E_{\max }$ values are normalized to CP55940 for CB1R assay and to 5-HT for 5-HT ${ }_{1 A} R$ assays. ND, no detectable efficacy, ${ }^{a}$ pEC ${ }_{50}$ cannot be determined, ${ }^{b} E_{\max }$ cannot be determined as it is within $\pm 10 \%,{ }^{c} E_{\max }$ or $I_{\max }$ cannot be determined as it is within $100 \pm 10 \%$. One-way analysis of variance followed by post hoc Tukey test was used. $p<0.05$ against ${ }^{*}$ CP55940 (in CB1R/Gi assay) and ${ }^{*} 5-\mathrm{HT}$ (in $5-$ $\mathrm{HT}_{1 \mathrm{~A}} \mathrm{R} / \mathrm{Gi}, 5-\mathrm{HT} 1 \mathrm{AR} / \mathrm{Gi}+5-\mathrm{HT}$, or 5-HT ${ }_{1 \mathrm{~A}} \mathrm{R} / \mathrm{cAMP}$ assay). 
Supplementary Table 2. Allosteric binding properties of AM2201. Data were fit by sigmoidal dose-response relationship against 5-HT concentration for $\left[{ }^{3} \mathrm{H}\right]$ WAY100635 (Fig. 4a). $\mathrm{K}_{\mathrm{i}}$ and specific binding values are means \pm S.E.M. of 3 or more experiments performed in triplicate. Specific binding values are normalized to $0 \mu \mathrm{M}$ AM2201.

\begin{tabular}{|c|c|c|}
\hline \multirow{2}{*}{$\begin{array}{c}\text { AM2201 } \\
(\mu \mathrm{M})\end{array}$} & \multicolumn{2}{|c|}{ with 5-HT } \\
\cline { 2 - 3 } & $\left.{ }^{3} \mathrm{H}\right]$ W & Specific binding $(\%)$ \\
\hline 0 & $5.79 \pm 0.03$ & $100 \pm 0.5$ \\
\hline 30 & $5.73 \pm 0.03$ & $88.8 \pm 0.7^{\mathrm{a}}$ \\
\hline
\end{tabular}

ap $<0.05$ compared with $0 \mu \mathrm{M}$ AM2201 (one-way analysis of variance, followed by post hoc Tukey test). 


\section{REFERENCES}

1. Guan, X. M.; Kobilka, T. S.; Kobilka, B. K., Enhancement of membrane insertion and function in a type IIlb membrane protein following introduction of a cleavable signal peptide. J Biol Chem 1992, 267 (31), 21995-8.

2. Yano, H.; Provasi, D.; Cai, N. S.; Filizola, M.; Ferre, S.; Javitch, J. A., Development of novel biosensors to study receptor-mediated activation of the G-protein alpha subunits Gs and Golf. J Biol Chem 2017, 292 (49), 19989-19998.

3. Bonifazi, A.; Yano, H.; Guerrero, A. M.; Kumar, V.; Hoffman, A. F.; Lupica, C. R.; Shi, L.; Newman, A. H., Novel and Potent Dopamine D2 Receptor Go-Protein Biased Agonists. ACS Pharmacol Transl Sci 2019, 2 (1), 52-65.

4. Bonifazi, A.; Yano, H.; Ellenberger, M. P.; Muller, L.; Kumar, V.; Zou, M. F.; Cai, N. S.; Guerrero, A. M.; Woods, A. S.; Shi, L.; Newman, A. H., Novel Bivalent Ligands Based on the Sumanirole Pharmacophore Reveal Dopamine D2 Receptor (D2R) Biased Agonism. J Med Chem 2017, 60 (7), 2890-2907.

5. Zou, M. F.; Keck, T. M.; Kumar, V.; Donthamsetti, P.; Michino, M.; Burzynski, C.; Schweppe, C.; Bonifazi, A.; Free, R. B.; Sibley, D. R.; Janowsky, A.; Shi, L.; Javitch, J. A.; Newman, A. H., Novel Analogues of (R)-5-(Methylamino)-5,6-dihydro-4H-imidazo[4,5,1ij]quinolin-2(1H)-one (Sumanirole) Provide Clues to Dopamine D2/D3 Receptor Agonist Selectivity. J Med Chem 2016, 59 (7), 2973-88.

6. Cheng, Y.; Prusoff, W. H., Relationship between the inhibition constant (K1) and the concentration of inhibitor which causes 50 per cent inhibition (I50) of an enzymatic reaction. Biochem Pharmacol 1973, 22 (23), 3099-108.

7. Zimmer, A.; Zimmer, A. M.; Hohmann, A. G.; Herkenham, M.; Bonner, T. I., Increased mortality, hypoactivity, and hypoalgesia in cannabinoid CB1 receptor knockout mice. Proc Natl Acad Sci U S A 1999, 96 (10), 5780-5. 
8. Hoffman, A. F.; Laaris, N.; Kawamura, M.; Masino, S. A.; Lupica, C. R., Control of cannabinoid CB1 receptor function on glutamate axon terminals by endogenous adenosine acting at A1 receptors. J Neurosci 2010, 30 (2), 545-55. 